\title{
Health Emergency Response Readiness of Undergraduate Student
}

\author{
P. P. L. Or \\ Department of Health and Physical Education, The Education University of Hong Kong, Hong Kong (SAR), China \\ Email:peggyor@yahoo.com
}

How to cite this paper: Or, P.P.L. (2017) Health Emergency Response Readiness of Undergraduate Student. Health, 9, 393-400. https://doi.org/10.4236/health.2017.93027

Received: January 18, 2017

Accepted: March 6, 2017

Published: March 9, 2017

Copyright $\odot 2017$ by author and Scientific Research Publishing Inc. This work is licensed under the Creative Commons Attribution International License (CC BY 4.0).

http://creativecommons.org/licenses/by/4.0/

\begin{abstract}
The increased threats of terrorism, disease outbreak and natural disasters clearly support the need to incorporate health emergency education into the school curricula to enhance emergency awareness and the development of Emergency Response Management Plans. The purpose of this study was to explore the health emergency response readiness of the undergraduate students upon completion of a "Health Emergency Education" course in Hong Kong. Thirty-three undergraduate students (aged from 19 to 23) enrolled in the course were selected for investigation. A 21-item semi-structured class exercise was administered to the students before and after the course. A significant improvement in the knowledge of emergency signage was observed. There was a strong positive correlation between the participants' knowledge of performing the cardiopulmonary resuscitation $(\mathrm{CPR})$ and their confidence in giving first aid to friends $(\mathrm{r}=0.81, \mathrm{p}=0.00)$. The participants were more confident in administering first aid to family members and friends than strangers and the findings in this study were consistent with previous studies. The elective course significantly increased the students' health emergency knowledge and confidence to provide assistance in an emergency situation. It is important to accompany advisories with educational messages to help the public understand emergency risks and enhance response readiness.
\end{abstract}

\section{Keywords}

Health Emergency Education, Response Readiness, Cardiopulmonary Resuscitation

\section{Introduction}

Emergency is an urgent situation demanding, sometimes, instantaneous decisions and follow-up actions. It is usually confined in time and space. Intrinsically it implies rules of engagement and exit strategies, and it relates best to active and 
apt responses. Health emergency is an occurrence or imminent threat to a health condition, which may be caused by bioterrorism or epidemic infectious diseases that pose a substantial risk to a significant number of people or cause long-term disability [1].

Since the terrorist attacks of 2001 in the United States, considerable effort has been expended to assess the worldwide capacity and capability of the public health systems to detect, prevent, prepare, and response to terrorist incidents. Emergency threats to public health by countries are broad and diverse including unsafe food and water, infectious disease outbreaks, natural disasters, chemical and radiation contamination, and terrorism and social instability events. Severe acute respiratory syndrome (SARS) (2003), Swine influenza A (2009), Middle East respiratory syndrome (2015), and recent Zika virus are examples of infectious disease outbreaks emerging in one country and subsequently spreading rapidly to many others. These outbreaks could cause disproportionate catastrophic economic losses to the infected countries.

To meet these challenges, the World Health Organization (WHO) encourages countries to strengthen their capacities for emergency risk management by incorporating measures for awareness, prevention, preparedness, response, and recovery [1]. It is crucial for people to safeguard their health outcomes at risk of emergencies and to be able to manage the associated health risks. In July 2016, Hong Kong had its first direct encounter with terrorism when a family travelling overseas was attacked by a terrorist in south Germany. People equipped with knowledge and skills can save lives and are mentally prepared for emergency situations. They will have increased confidence in handling emergencies and a sense of contribution to the community. Youngsters are good about helping one another in personal health emergencies such as choking, bleeding, and allergic reactions. The current increased threats of terrorism, disease outbreaks and natural disasters clearly support the need to incorporate health emergency education into school curricula to enhance emergency awareness and the development of Emergency Response Management Plans. With this education, the general public are better equipped to use coordinated and proper approaches to emergency preparedness and response [2] [3].

This study selected undergraduate students who enrolled in the elective course "Health Emergency Education" as participants since they would work in the healthcare profession in future and should be properly and adequately prepared to respond to social instability, terrorism, disease outbreaks, and other health emergencies. The students were trained with a specially designed education programme which could increase their awareness of risks, enhance their communication skills, and boost their overall confidence in tackling health emergencies, especially for those students studying health-related subjects. Since emergencies have a limited timeframe for actions and people would benefit from strong coordination and clear chains of command, the effectiveness of the emergency response can ultimately hinge on the quality of decision-making. It is important to accompany advisories with educational messages designed to help the public understand emergency 
risks and the corresponding appropriate responses. It was aimed that this course would foster a stronger sense of community in students by instilling life skills in handling emergencies.

In Hong Kong, programmes which provide health emergency education are mainly for health professionals in medicine, nursing, and Chinese medicine. To strengthen public resilience, the education sector plays a pivotal role in promulgating health emergency awareness and response. The context of the present study is to evaluate the health emergency response readiness of undergraduate students who had completed the elective course on health emergency education which focused on developing responses and health literacy towards health emergencies. The course content included personal and public health events, environmental pollution, social instability, infectious disease outbreaks, and natural disasters. It aimed to enhance students' capability in judgment, decision-making, risk communication, and coordination to prepare for and manage emergencies and public crisis. Upon the successful completion of the course, students should be able to: 1) identify the categories and scope of health emergencies; 2) design an education programme to be implemented for health emergency response and management in the community.

\section{Objectives}

1. Identify the undergraduate students' awareness to and basic knowledge on health emergencies;

2. Identify the undergraduate students' level of confidence in helping people in emergency situations.

\section{Methods}

This is a retrospective study design to analyze the class exercise of undergraduate students enrolled in the elective course "Health Emergency Education" in the second semester of the academic year 2015-2016. Participants were randomly selected who enrolled in the course. Ethics approval was obtained from the $\mathrm{Hu}$ man Research Ethics Committee from the University. Thirty-three undergraduate students (19 to 23 years old) were enrolled in this course. In addition to collecting students' demographic data, the class exercise consisted of three other parts. The first part had 7 questions about emergency signage. For each signage, the participants were asked: 1) what meaning they attached to it, and 2) what actions they should take. Seven emergency signages were: exit, landslide, emergency shower, emergency stop button, emergency telephone, automated external defibrillator (AED) and biohazard. The second part consisted of 9 questions on health emergency knowledge. Nine questions such as what is the emergency call in the United States; what kind of food always has food poisoning? The third part consisted of 3 questions and participants were asked about their level of confidence in helping other people in emergency situations, using a five-point Likert scale on the level of confidence with 1 being the lowest and 5 being the highest. This 21-item semi-structured class exercise was administered to the stu- 
dents before the first lecture and after the last lecture. This class exercise was administered as a survey and was not part of the course. Internal consistency of the class exercise was performed and the value of Cronbach's alpha was 0.87 , indicating good reliability.

\section{Results}

Thirty-three students were enrolled in the course $(\mathrm{N}=33)$ and they completed the pre-course measure ( $\mathrm{C} 1)$ and the class exercise (C2) after the course had finished. The class statistics were male students (27.3\%) and female students (72.7\%), full-time students (81.8\%) and part-time students (18.2\%), and students with CPR training (54.5\%) (Table 1 ).

\subsection{Emergency Signage}

Participants were asked to label the emergency signage and explain what they should do when they saw the signs. The selected signage is easy to find in Hong Kong, like landslide warning (Figure 1), which is issued by the Hong Kong Observatory when there is a high risk of landslips as a result of persistent heavy rainfall. Significant improvements were gained in the knowledge of emergency signage like landslide from $78.8 \%$ to $97.0 \%$, emergency shower from $60.6 \%$ to $81.8 \%$, biohazard from $45.5 \%$ to $75.8 \%$, and travel health kit from $64.3 \%$ to $81.5 \%$. It was also found that $81.8 \%$ of the participants could recognize automated external defibrillator (AED) signage (Figure 2) before the course and a higher $97.0 \%$ of the participants could recognize AED signage after the course (Table 2).

\subsection{Emergency Telephone Number}

Participants were asked about the emergency calls in different countries. After the course, more participants could recall the emergency numbers correctly, rising from $48.5 \%$ to $63.6 \%$ for Mainland China and $66.7 \%$ to $87.9 \%$ for the United

Table 1. Demographic distribution $(\mathrm{N}=33)$.

\begin{tabular}{ccc}
\hline Variable & & $\mathrm{n}(\%)$ \\
\hline Sex & Male & $9(27.3)$ \\
& Female & \\
Age & $19-20$ & $24(72.7)$ \\
& $21-22$ & $9(27.3)$ \\
& 23 & $2(66.7)$ \\
Study mode & Full time & $27(81.8)$ \\
& Part time & $6(18.2)$ \\
CPR training & Yes & $18(54.5)$ \\
& No & $15(45.5)$
\end{tabular}




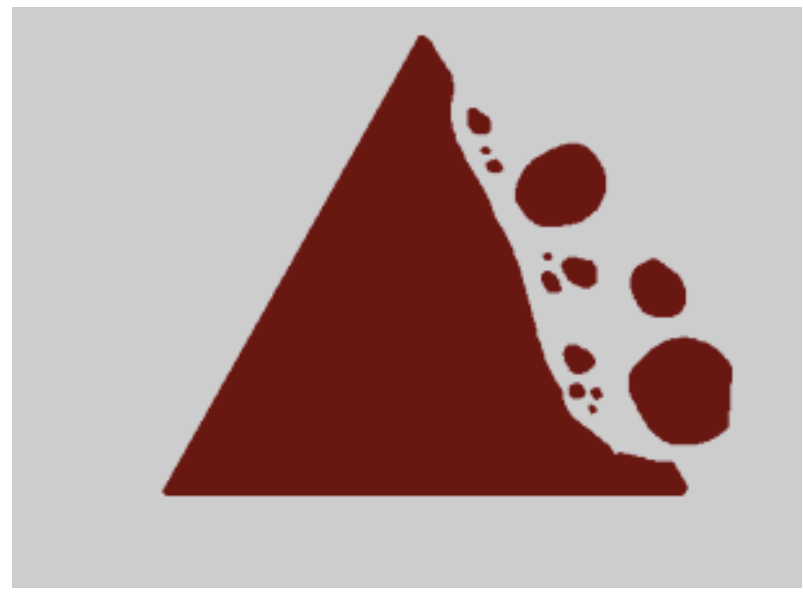

Figure 1. The landslip warning.

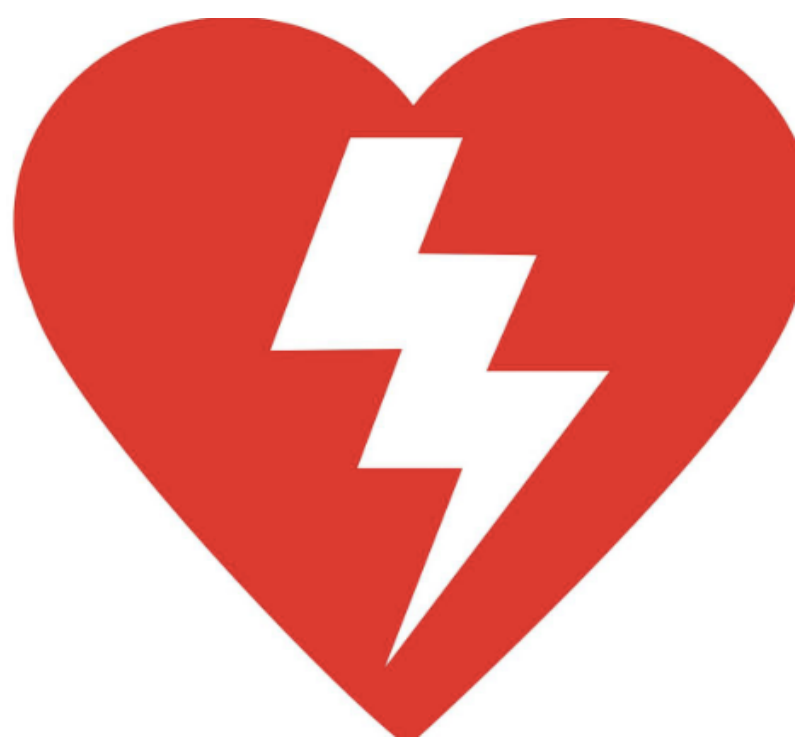

Figure 2. Automated External Defibrillator (AED).

Table 2. Results of knowledge of emergency signage compared pre and post results $(\mathrm{N}=$ $33)$.

\begin{tabular}{ccc}
\hline Sign & Pre-test $\mathrm{n}(\%)$ & Post-test $\mathrm{n}(\%)$ \\
\hline Exit & $27(81.8)$ & $32(97.0)$ \\
Landslide & $26(78.8)$ & $32(97.0)$ \\
Emergency shower & $20(60.6)$ & $27(81.8)$ \\
Emergency stop bottom & $13(39.3)$ & $15(45.5)$ \\
Emergency telephone & $26(78.8)$ & $29(87.9)$ \\
Automated External Defibrillator (AED) & $27(81.8)$ & $32(97.0)$ \\
Biohazard & $15(45.5)$ & $25(75.8)$ \\
\hline
\end{tabular}

States. An independent sample t-test was performed and the result showed a significant difference in the knowledge of emergency calls in Mainland China ( $\mathrm{p}=$ 0.01). 


\subsection{Public Health Information}

Participants were asked about the real-time Air Quality Index in the campus region to arouse their awareness towards the air pollution situation in Hong Kong. Less than one third of the participants could answer correctly both before and after the course. Overall, they performed poorly on this question. For food safety knowledge, participants were asked what kind of food causes food poisoning. The number of participants who could answer correctly was nearly the same before and after the course.

\subsection{Cardiopulmonary Resuscitation}

On administration of Cardiopulmonary resuscitation (CPR), the students were asked if they knew that the compressions-to-breaths ratio was 30:2, with both numbers in the correct order. Nearly half of the participants (51.5\%) gave the correct answer after the course. Independent sample t-test was performed and the result showed a significant difference in knowing the compressions-to-breathes ratio in performing CPR $(\mathrm{p}=0.01)($ Table 3$)$.

\subsection{Confidence in Giving First Aid}

The participants rated their level of confidence in providing first aid to "a family member", "a friend", and to "a stranger" in an emergency situation. Ratings were made on a five-point Likert scale rating from 1 ("not at all confident") to 5 ("very confident"). They reported increased confidence in assisting, before and after the course, their family members (from $35.7 \%$ to $59.2 \%$ ), their friends (from $39.3 \%$ to $59.2 \%$ ), and strangers (from $32.1 \%$ to $48.1 \%$ ). Independent sample t-test was performed and the results showed a significant difference in providing first aid to family members $(p=0.03)$. Different types of people were compared with the analysis of variance (ANOVA). There was statistical significance ( $p=0.04$ ) on the level of confidence in administrating first aid to strangers. Also there was a strong positive correlation between the participants' knowledge on performing CPR and the level of confidence in giving first aid to their friends $(\mathrm{r}=0.81, \mathrm{p}=0.01)$ and strangers $(\mathrm{r}=0.80, \mathrm{p}=0.01)$, indicating that the relationship between first aid knowledge and administrating first aid to friends and strangers was statistically significant. For gender, the Chi-square test was performed and there was a significant difference in the level of self-confidence in gender $(\mathrm{p}=0.04)$ (Table 4) about giving first aid to a friend in an emergency situation. However, there was no significant difference in participants' study mode in administering first aid in an emergency situation.

\section{Discussion}

There was a substantial gain in the knowledge of emergency signage, especially the landslide signage because landslide is one of the common phenomena in Hong Kong. The signages were easy to understand and participants were familiar with these phenomena. Surprisingly, participants' knowledge of the AED signage was quite high before the course and they could recognize the signage even 
Table 3. Six questions on health emergency knowledge $(\mathrm{N}=33)$.

\begin{tabular}{cccc}
\hline Questions & $\begin{array}{c}\text { Pre-test } \mathrm{n} \\
(\%)\end{array}$ & $\begin{array}{c}\text { Post-test } \mathrm{n} \\
(\%)\end{array}$ & $\begin{array}{c}\mathrm{p}^{*} \\
(<0.05)\end{array}$ \\
\hline $\begin{array}{c}\text { What is the emergency call in United States? } \\
\text { What is the emergency call in mainland China? }\end{array}$ & $22(66.7)$ & $29(87.9)$ & 0.23 \\
What to pack in your travel health kit? & $22(66.7)$ & $27(81.5)$ & 0.06 \\
$\quad$ Today air quality index? & $8(24.2)$ & $10(30.3)$ & 0.16 \\
$\begin{array}{c}\text { What kind of food always has food poisoning? } \\
\text { When performing CPR, how many compressions to } \\
\text { breaths? }\end{array}$ & $26(78.8)$ & $25(75.8)$ & 0.06 \\
\hline
\end{tabular}

*Significant when $\mathrm{p}<0.05$.

Table 4. Confidence in giving first aid.

\begin{tabular}{cccc}
\hline Giving first aid to the following people & mean \pm SD & ANOVA & $\mathrm{p}^{*}$ \\
\hline & $(\mathrm{N}=33)$ & F ratio & $(<0.05)$ \\
A family member & $3.52 \pm 2.34$ & 1.56 & 0.23 \\
A friend & $3.59 \pm 2.24$ & 3.30 & 0.08 \\
Someone you do not know & $3.48 \pm 2.31$ & 4.73 & 0.04 \\
\hline
\end{tabular}

${ }^{*}$ Significant when $\mathrm{p}<0.05$.

without any previous cardiopulmonary resuscitation (CPR) training. This may be because the Leisure and Cultural Services Department of Hong Kong has installed more than 300 AEDs in around 250 public areas including parks, playgrounds, beaches, sport centres, cultural spots, and public libraries since 2013, which have aroused the public awareness of first aid treatments in public areas.

For the emergency telephone numbers, more participants could recall emergency numbers of the United States than that of Mainland China. This reflects that they might be influenced by American movies and the September 11 attacks news [4]. The participants did not perform well in communicating public health information, particularly the air pollution situation in Hong Kong. They were not familiar with the Air Quality Index (AQI), possibly because the Air Pollution Index which had been used for 18 years was recently replaced by Air Quality Index in 2013 [5]. Moreover, the majority of the participants did not have existing heart or respiratory illness and so it was not necessary for them to check the AQI daily before making any decisions on outdoor physical activities. Half of the participants had attended the CPR training before the course but less than $35 \%$ of them could answer the question on compressions to breaths ratio correctly; however, more than half of them knew the correct answer after the course. This finding showed that the course was helpful and the students simply applied what they had learnt in emergency situations.

On the other hand, the participants were more confident in administering first aid to family members and friends than strangers. The finding was consistent with previous studies [4] [6] [7]. It is worth mentioning that CPR training can boost one's confidence in helping other people in emergencies. There was 
significant difference in gender self-confidence about giving first aid to a friend in an emergency situation and the result was similar to that of Benin Laner and Ventrone's study [8]. There was a significant interaction between gender of bystanders and victims, such as men are most likely to intervene to aid women.

Based on the results of this study, the participants had more confidence in administering first aid in emergency situations if they had more knowledge in health emergency. This course could foster a stronger sense of community in students by instilling life skills, enhancing risk communication, developing preparedness and generating response towards health emergency situations.

\section{Conclusion}

The elective course could significantly raise students' health emergency knowledge and confidence to provide assistance in an emergency situation. The findings in this study reinforced the value that specific school-based training could provide a general foundation for emergency response readiness. The effectiveness of the emergency response can ultimately hinge on the quality of decisionmaking. It is important to accompany advisories with appropriate educational messages to help the public understand the emergency risks and prepare them for response readiness.

\section{References}

[1] World Health Organization (2015) Sendai Framework for Disaster Risk Reduction. http://www.who.int/hac/techguidance/preparedness/en/

[2] Markenson, D., DiMaggio, C. and Redlener, I. (2005) Preparing Health Professions Students for Terrorism, Disaster, and Public Health Emergencies: Core Competencies. Academic Medicine, 80, 517-526. https://doi.org/10.1097/00001888-200506000-00002

[3] Smith, R.D. (2006) Responding to Global Infectious Disease Outbreaks: Lessons from SARS on the Role of Risk Perception, Communication and Management. Social Science \& Medicine, 63, 3113-3123. https://doi.org/10.1016/j.socscimed.2006.08.004

[4] Wilks, J., Kanasa, H., Pendergast, D. and Clark, K. (2015) Emergency Response Readiness for Primary School Children. Australian Health Review. A Publication of the Australian Hospital Association, 40.

[5] Environmental Protection Department (2016) Air Quality in Hong Kong. http://www.weather.org.hk/english/aqi.html

[6] Kindersley, D. (2014) New Study Reveals Individual's Lack of Confidence to Perform CPR. Absence Management November 21.

http://www.workplacemedical.com/new-study-showcases-individuals-lack-confiden ce-perform-cpr/

[7] De Vijver, E.V. and Devroey, D. (2013) Lack of Confidence in Administering Emergency Care among Dutch-Speaking Family Physicians in Belgium. International Journal of General Medicine, 6, 589-596. https://doi.org/10.2147/IJGM.S46432

[8] Benin, M.H., Laner, M.R. and Ventrone, N.A. (2001) Bystander Attitudes toward Victims of Violence: Who's Worth Helping. An Interdisciplinary Journal, 22, 23-42. 
Submit or recommend next manuscript to SCIRP and we will provide best service for you:

Accepting pre-submission inquiries through Email, Facebook, LinkedIn, Twitter, etc. A wide selection of journals (inclusive of 9 subjects, more than 200 journals)

Providing 24-hour high-quality service

User-friendly online submission system

Fair and swift peer-review system

Efficient typesetting and proofreading procedure

Display of the result of downloads and visits, as well as the number of cited articles Maximum dissemination of your research work

Submit your manuscript at: http://papersubmission.scirp.org/

Or contact health@scirp.org 